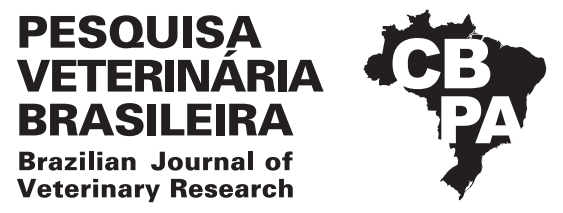

Pesq. Vet. Bras. 38(8):1475-1483, agosto 2018 DOI: 10.1590/1678-5150-PVB-5265

Artigo Original

Animais de Produção/Livestock Diseases

ISSN 0100-736X (Print)

ISSN 1678-5150 (Online)

\title{
Anemia hemolítica em bovinos de corte em sistema de criação extensiva em Mato Grosso e Rondônia ${ }^{1}$
}

\author{
Leilane A.S. Rondelli², Marciel Becker², Flávio H.B. Caldeira ${ }^{2}$, Marlon Ribeiro ${ }^{3}$, \\ Fernando H. Furlan ${ }^{2}$, Edson M. Colodel ${ }^{2}$, Caroline A. Pescador ${ }^{2}$ \\ e Nadia A.B. Antoniassi ${ }^{3 *}$
}

\begin{abstract}
Rondelli L.A.S., Becker M., Caldeira F.H.B., Ribeiro M., Furlan F.H., Colodel E.M., Pescador C.A. \& Antoniassi N.A.B. 2018. [Hemolytic anemia in beef cattle in extensive system farming in Mato Grosso and Rondônia.] Anemia hemolítica em bovinos de corte em sistema de criação extensiva em Mato Grosso e Rondônia. Pesquisa Veterinária Brasileira 38(8):1475-1483. Faculdade de Veterinária, Universidade Federal de Mato Grosso, Av. Fernando Corrêa da Costa 2367, Boa Esperança, Cuiabá, MT 78060-900, Brazil. E-mail: naassi@gmail.com

Cases of hemolytic anemia in beef cattle in na extensive breeding system in Mato Grosso and Rondônia have been monitored since 2008. The affected animals presented weakness, pale or icteric mucosas, blackened urine, prostration and anorexia. The outcome of these cases often is death, principally if the animals are forced to walk. Approximately 429 cattle died in these outbreaks andin some of these, mortality rates ranged from 0.26 to $50 \%$. Research was carried out on the main infectious causes such as leptospirosis, babesiosis, trypanosomiasis, anaplasmosis and bacillary hemoglobinuria, as well as the possible toxic causes reported as etiology of hemolytic anemia in cattle through hematology, blood biochemistry, molecular and histopathological examinations. Any plant ready described in Brazil as cause of hemolytic anemia in animals from livestock interest was observed in thosefarms. Although the etiology of these cases is not yet known, clinical and pathological evidences of the disease suggested that it is caused by a toxic plant of hemolytic action, present in the affected properties, but not yet confirmed experimentally.
\end{abstract}

INDEX TERMS: Hemolytic anemia, beef cattle, extensive farming, Mato Grosso, Rondônia, hemoglobinuria, hemolytic poisoning, cattle.

RESUMO.- Casos de anemia hemolítica em bovinos de corte em sistema de criação extensiva em Mato Grosso e Rondônia são acompanhados desde 2008. Os animais acometidos apresentam fraqueza, mucosas pálidas ou ictéricas, urina enegrecida, depressão e anorexia. Esse quadro muitas vezes evolui para morte, principalmente quando os animais são movimentados. Durante esse período aproximadamente 429 bovinos morreram em diferentes surtos eem alguns

\footnotetext{
${ }^{1}$ Recebido em 5 de julho de 2017.

Aceito para publicação em 30 de julho de 2017.

${ }^{2}$ Laboratório de Patologia Veterinária, Hospital Veterinário, Faculdade de Veterinária, Universidade Federal de Mato Grosso, Av. Fernando Corrêa da Costa 2367, Boa Esperança, Cuiabá, MT 78060-900, Brasil. E-mails: leilane_go@hotmail.com, marcielbecker@hotmail.com, flaviobcaldeira@gmail. com, fhfurlan@gmail.com, moleta@gmail.com, carolpescador@yahoo.com.br

${ }^{3}$ Laboratório de Patologia Animal, Hospital Veterinário, Instituto de Ciências da Saúde, Universidade Federal de Mato Grosso, Campus Sinop, Av. Alexandre Ferronato 1200, Distrito Industrial, Sinop, MT 78550-000, Brasil. E-mails: marlonribeiro86@gmail.com; *Autor para correspondência: naassi@gmail.com
}

casos a mortalidade chegou a 50\%. Foi realizada investigação para as principais causas infecciosas como leptospirose, babesiose, tripanossomíase, anaplasmose e hemoglobinúria bacilar, bem como para as possíveis causas toxicas relatadas como etiologia de anemia hemolítica em bovinos por meio de exames hematológicos, bioquímica sanguínea, moleculares e histopatológicos. Não se observou nas propriedades acometidas, nenhuma das plantas já descritas no Brasil como causadora de anemia hemolítica em animais de interesse pecuário no momento das investigações dos surtos. Apesar da etiologia desses casos ainda não ser conhecida, as evidências epidemiológicas, clínicas e patológicas da doença sugerem que a mesma seja causada por uma planta tóxica de ação hemolítica, presente nas propriedades acometidas, mas que ainda não foi confirmada experimentalmente.

TERMOS DE INDEXAÇÃO: Anemia hemolítica, bovinos de corte, criação extensiva, Mato Grosso, Rondônia, hemoglobinúria, planta hemolítica, intoxicação. 


\section{INTRODUÇÃo}

Anemia hemolítica é a destruição prematura de hemácias sem o aumento da taxa de reposição (Fry \& McGavin 2013) e é classificada em função do mecanismo de hemólise, localização (intravascular/extravascular), fisiopatologia (imunes/não imunes) e dependendo da velocidade de instauração (agudas/crônicas) (Berenguer Piqueras et al. 2016). Se caracteriza clinicamente por dispneia, intolerância ao exercício, palidez das mucosas, aumento da frequência cardíaca, hemoglobinemia, icterícia, hemoglobinúria, febre, e depressão (Lopes et al. 2007). Dentre as causas de anemia hemolítica em bovinos destacamse as doenças infecciosas, como leptospirose, babesiose, tripanossomíase, anaplasmose e hemoglobinúria bacilar (Riet-Correa et al. 2001, Schild et al. 2008, Cadioli et al. 2012, Silva et al. 2013, 2015), as doenças de causas tóxicas, como a intoxicação por cobre (Aquino Neto et al. 2014) e por plantas tóxicas. Brachiaria radicans "tanner-grass", forrageira utilizada para ruminantes e presente em quase todo o território nacional tem sido relatada como causadora de quadros de anemia hemolítica, nos Estados de São Paulo e Santa Catarina (Gava et al. 2010, Tokarnia et al. 2012) e neste último, foi relatado um surto de intoxicação por Allium cepa em búfalos com quadro de anemia hemolítica (Borelli et al.2009). Além destas, há relatos de intoxicação por Ditaxis desertorum com importância limitada ao Estado da Bahia (Tokarnia et al. 1997, 2012) e Indigofera suffruticosa, popularmente conhecida como "anil", que causa intoxicações em bovinos na região nordeste do país (Figueiredo et al. 2012). Foram relatadas intoxicações, de bovinos por óleo de Brassica napus L. nos Estados Unidos, Canadá, Grã-Bretanha e Irlanda, de bovinos e ovinos por Brassica oleracea var. acephalanos Estados Unidos, Grã-Bretanha e de bovinos por Allium canadense e Allium schoenoprasm nos Estados Unidos (Burrows \&Tyrl 2013). Casos de intoxicação por Acer rubrum (Maple vermelho) foram descritos nos Estados Unidos em alpacas (De Witt et al. 2004), equinos (Alward et al. 2006) e Zebras (Weber \& Miller 1997).

Uma enfermidade de caráter hemolítico é frequentemente observada em bovinos de criação extensiva, desde o ano de 2008 nos Estados de Mato Grosso e Rondônia. Nenhuma das causas conhecidas como hemolíticas foram identificadas e evidências indicam como causa da doença uma planta tóxica ainda não identificada. Diante disso, o objetivo deste estudo é descrever os aspectos epidemiológicos, clínicos e anatomopatológicos da doença hemolítica que acomete bovinos em surtos acompanhados pela equipe do Laboratório de Patologia Veterinária (LPV) e Laboratório de Patologia Animal (LAPAN) da Universidade Federal de Mato Grosso (UFMT), Campus Cuiabá e Sinop.

\section{MATERIAL E MÉTODOS}

No período de 2008 a 2016, nove surtos de doença hemolítica em bovinos foram acompanhados pelas equipes do LPV-UFMT e do LAPAN-UFMT, oito nos Estado de Mato Grosso e um em Rondônia. As propriedades em que ocorreram os surtos foram enumeradas em ordem crescente de acordo com a sequência cronológica (Surto 1 a 9), assim como os animais examinados (Bovino 1 a 18). No estado de Mato Grosso os Surtos 1 e 8 ocorreram em Juína, Surtos 3 e 4 em Porto dos Gaúchos, Surto 5 em Nova Ubiratã, Surto 6 em Matupá,
Surto 7 em Feliz Natal, Surto 9 em Terra Nova do Norte e no Estado de Rondônia o Surto 2 ocorreu no município de Nova Mamoré.

Dados epidemiológicos e clínicos foram obtidos junto aos proprietários e/ou médicos veterinários que atenderam as propriedades e em visitas realizadas pelas equipes durante os Surtos 1, 3, 4, 7 e 9. Adicionalmente, em 2016, as propriedades foram contatadas novamente com o objetivo de avaliar os surtos e averiguar a recorrência da doença. Destas, cinco propriedades $(1,3,4,5,9)$ foram revisitadas.

Dos nove surtos acompanhados, 18 bovinos foram acompanhados clinicamente, testes de hemogramas foram realizados com amostras de sangue de 8 bovinos dos Surtos 4, 7 e 9 pelo método da contagem automática de células, com a utilização do aparelho VET ABC-TM Micros 60, com cartão de leitura de hematócrito para bovinos, além da análise de esfregaço sanguíneo de 14 bovinos dos Surtos 1, 2, 3, 4, 7, 8 e 9 para análise morfológica celular e leucometria diferencial. Esfregaços de sangue total de 14 bovinos dos Surtos 1, 2, 3, 4, 7, 8 e 9, foram processados pela técnica do micro hematócrito (Batista et al. 2008), corados com Panótico ${ }^{\circledR}, \mathrm{e}$ analisados por microscopia direta para pesquisa de Trypanosoma spp., Babesia spp. e Anaplasma spp. Exames séricos de ureia, creatinina e dosagem das enzimas hepáticas como Gama glutamiltransferase (GGT), Creatinofosfoquinase (CK) Alanina aminotransferase (ALT), Fosfatase Alcalina (FA) e Desidrogenase láctica (LDH). Valores de Bilirrubina total e Albumina foram obtidos utilizando kits da Bioclin ${ }^{\circledR} \mathrm{e}$ procedeu-se de acordo com as recomendações do fabricante. Amostras de urina foram analisadas pelo método de urinálise para observação de caracteres físicos macroscópicos, pesquisa semi-quantitativa e sedimentoscopia microscópica quantitativa, e por avaliações através de fita reagente (Hemagen ${ }^{\circledR}$ ). A diferenciação entre mioglobinúria e hemoglobinúria foi realizada na urina de 4 bovinos dos Surtos 4 e 8 , pela técnica qualitativa do Sulfato de Amônio. Foram adicionados 2,8g de Sulfato de amônio em $5 \mathrm{ml}$ de urina, com posterior centrifugação a 2000rpm por 10 minutos e 5 minutos em repouso, com a passagem de uma fita reagente (Hemagen ${ }^{\circledR}$ ) no filtrado (Lopes et al. 2007).

DNA foi extraído a partir de amostras de $250 \mu \mathrm{l}$ de sangue pertencentes a quatro bovinos dos Surtos 2, 3, 4 e 5, usando o método padrão fenol - clorofórmio e precipitação com etanol (Sambrook \& Russel 2001) e também a partir de amostras de rim, fígado e baço dos mesmos bovinos, fixadas em formalina a $10 \%$ e incluídas em parafina, de acordo com a técnica descrita por Shi et al. (2004). O DNA obtido foi analisado em eletroforese com gel de agarose $1 \% \mathrm{e}$ corado com brometo de etídeo (Sambrook et al. 1989). A presença de Tripanossoma spp., Babesia spp., Anaplasma sp. e Leptospira spp. nas amostras do DNA extraído foram testadas por reação em cadeia da polimerase (PCR). Na detecção de algum agente da família Anaplasma foi utilizado o primer GE2'F2' e HE3 de acordo com protocolo descrito por Melo et al. (2016). Para o gênero Babesia foi utilizado o gene 18S de acordo com Almeida et al. (2012). Para Trypanosoma spp. o protocolo utilizado foi de acordo com Cortez et al. (2009), utilizando o kit GFX ${ }^{\text {tm }}$ PCR DNA. Para Leptospira spp. foram utilizados os primers LipL32-45F e LipL32-286R desenhados por Stoddard et al. (2009) que tem o gene LipL32 como alvo específico para leptospiras patogênicas.

Quinze bovinos foram submetidos á necropsia. Alterações macroscópicas foram anotadas e fragmentos de tecidos foram coletados, fixados em formol a $10 \%$, e processados pelas técnicas histológicas rotineiras (Prophet et al. 1992), coradas pela hematoxilina e eosina (HE) e observados em microscopia óptica. Adicionalmente, foram realizadas as seguintes técnicas de colorações especiais em todos os casos: Ácido Rubeânico para detecção de Cobre em 
lâminas histológicas de fígado e rim; Warthin-Starry para detecção de espiroquetas de Leptospira sp. em lâminas histológicas de rim e a coloração de Perls para marcação de hemossiderina em lâminas de fígado e baço (Prophet et al. 1992).

\section{RESULTADOS}

\section{Epidemiologia e sinais clínicos}

No Estado de Mato Grosso as propriedades acometidas estão situadas no município de Juína (Surto 1 e 8), Porto dos Gaúchos (Surto 3 e 4), Nova Ubiratã (Surto 5), Matupá (Surto 6), Feliz Natal (Surto 7), e Terra Nova do Norte (Surto 9). No Estado de Rondônia a propriedade acometida situa-se no município de Nova Mamoré (Surto 2). Todas as propriedades se localizam nas regiões do bioma Amazônico e de transição
Cerrado-Amazônia e mantinham sistema de criação extensiva de bovinos nelore, com predomínio de cria e recria.

Nos Surtos 1, 2, 3, 5, 6 e 7 a doença ocorreu em somente um piquete da propriedade, nos Surtos 4 e 8, bovinos de dois piquetes foram acometidos e no Surto 9 foram em três piquetes. 0 tamanho dos piquetes variou de 50 a 750 hectares. Em todas as propriedades as pastagens dos piquetes onde ocorreram os surtos eram formadas e compostas por Brachiaria spp., com graus variados de degradação, ou sem degradação, com moderada à intensa quantidade de plantas daninhas (Fig.1A) e nas propriedades dos Surtos 5, 6 e 9 era realizado consórcio lavoura/pecuária. Esta vegetação invasora era composta por plantas comuns as regiões de mata de transição Cerrado-Amazônia e de Mata Amazônica, com especial destaque a planta Pleonotoma mieloides, observada

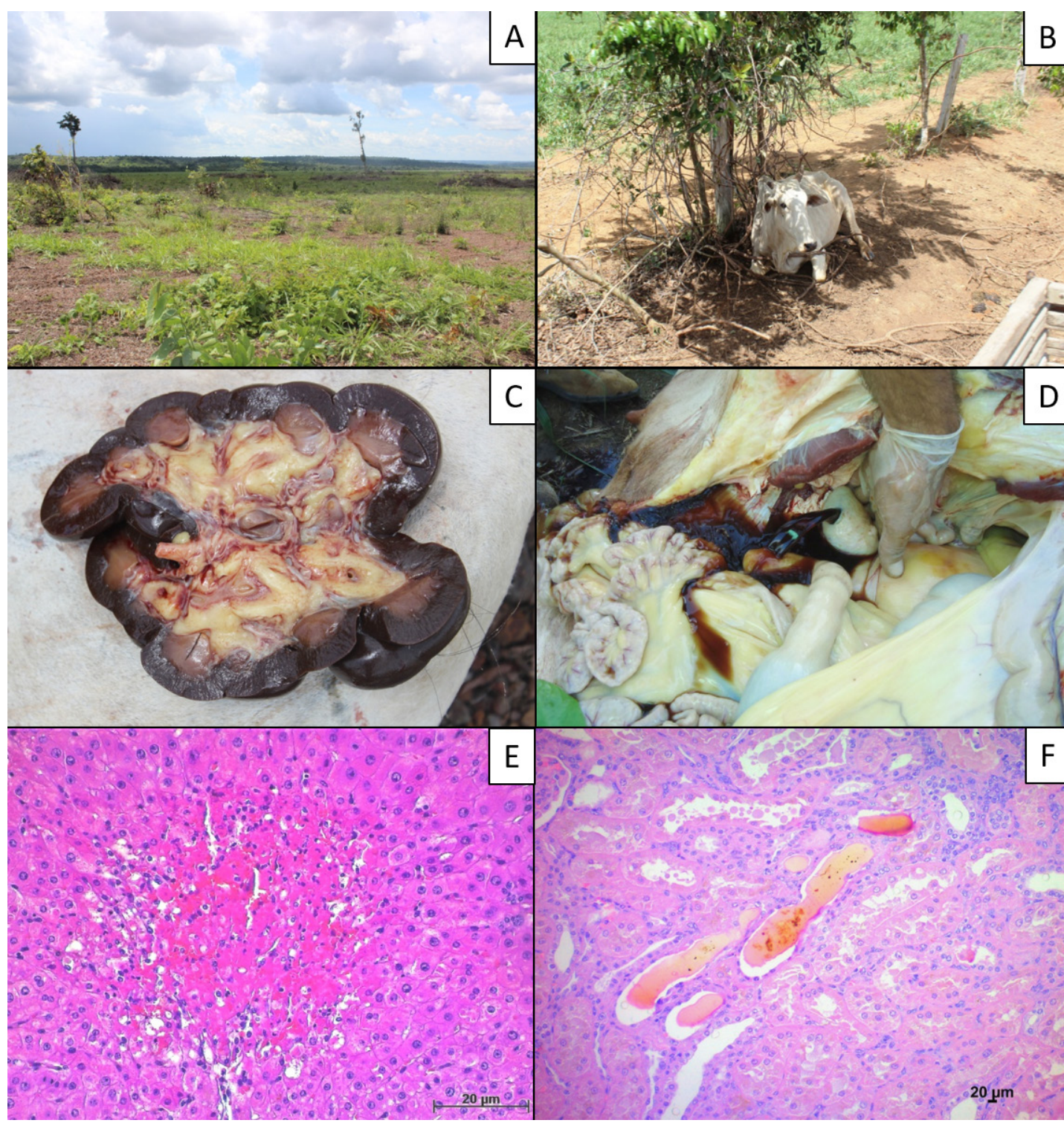

Fig.1. Anemia hemolítica tóxica em bovinos. (A) Piquete onde ocorreu um dos surtos, evidenciando pastagem recém formada por Brachiaria spp., com pouca disponibilidade de matéria verde e intensa invasão de plantas daninhas. (B) Bovino em decúbito esternal com fraqueza muscular e relutância a levantar-se. (C) Rim de coloração enegrecida. (D) Bexiga urinária contendo urina de coloração castanho escuro "cor de coca-cola". (E) Corte histológico de fígado com necrose paracentral de hepatócitos. HE, obj.40x. (F) Corte histológico de rim com nefrose hemoglobinúrica. HE, obj.20x. 
em todas as propriedades e com sinais de consumo pelos bovinos, mesmo quando havia boa disponibilidade de pastagem. Em nenhuma propriedade foram observadas plantas já descritas como hemolíticas como Brachiaria radicans, Allium cepa, Ditaxis desertorume, Indigofera suffruticosa (Tokarnia et al. 1997, Borelli et al. 2009, Gava et al. 2010, Figueiredo et al. 2012). Em todas as propriedades os animais eram suplementados com mineralização comercial especifica para bovinos.

Os bovinos dos Surtos 3, 4, e 6, comprados e recém introduzidos no rebanho, e os bovinos dos demais surtos, nativos, manifestavam sinais clínicos com 15 a 20 dias da chegada na propriedade ou da mudança dos piquetes, respectivamente. Iniciavam-se os sinais clínicos da doença e eram agravados após a movimentação dos animais e a evolução até a morte se dava de 1 a 5 dias. Aproximadamente 429 bovinos morreram nestes surtos. A mortalidade variou de 0,26 a $50 \%$, a morbidade foi de 0,57 a $67,11 \%$ e a letalidade apresentou variação de 22 a $100 \%$. Os surtos da doença ocorreram nos meses de outubro a junho, com maior ocorrência no mês de outubro. Informações epidemiológicas detalhadas a respeito dos surtos estão dispostas no Quadro 1.

Proprietários e veterinários de propriedades acometidas relatam que outros casos de mortalidade com sintomatologia semelhante ocorreram em diversas ocasiões em propriedades vizinhas ou próximas, mas não foram notificados.

Em todos os surtos os sinais clínicos eram semelhantes e caracterizavam-se inicialmente por palidez de mucosas (16/18 bovinos) e icterícia evidente em mucosas oral e ocular, por vezes de glândula mamária e tetos $(11 / 18)$, havia fraqueza acentuada (15/18), fadiga e picos de febre $(8 / 18)$ e com a evolução da doença havia quadros de depressão e tremores musculares acentuados (14/18), anorexia (8/18) e urina de coloração castanho escura em todos bovinos avaliados.
Frequentemente havia manifestações de agressividade (8/18), além de decúbito (Fig.1B). A evolução da doença incluía uma fase agônica final, onde a morte era de caráter agudo.

Tratamento suporte foi realizado nos bovinos dos Surtos 1, 2, 3, 4, 5, 6 e 9, porém, sem sucesso na recuperação. Os bovinos foram trocados de piquetes quando iniciaram as mortes em todos os surtos. Nessa movimentação houve a morte de alguns animais em quadro mais grave e posteriormente a recuperação dos demais ocorreu em poucos dias, apesar de ainda ocorrerem mortes nos Surtos 2, 4, 6 e 8, por um período de até 15 dias. Posteriormente, outros animais foram introduzidos nos piquetes, até 4 meses após os surtos. Nos Surtos 1, 7 e 9, a introdução de novos animais foi realizado após roçagem das pastagens, no Surto 2, após queima das mesmas e no Surto 4, nenhum manejo foi realizado na pastagem. Em todos os casos de reintrodução de animais, nenhuma manifestação clínica foi observada. A recorrência da doença não foi relatada em nenhum caso, com exceção da propriedade do Surto 4 em que relatos de funcionários indicam que um ano após o surto, alguns animais manifestaram sinais clínicos e morte semelhante aos casos de anemia hemolítica. Entretanto essa informação só foi obtida muito tempo após os casos. Nas propriedades dos Surtos 3, 5, 6 e 8, as pastagens foram substituídas por lavoura no ano subsequente, não havendo mais a criação de bovinos nestas áreas.

\section{Exames complementares}

$\mathrm{Na}$ análise estatística do eritrograma dos bovinos avaliados dos Surtos 4, 7 e 9 os valores da média e desvio padrão dos constituintes hematológicos são os descritos respectivamente: eritrócitos $(1,81$ e 0,29$)$, hemoglobina (3,55 e 1,14), hematócrito(10,16 e 3,03), VCM (55,19 e 10,25), CHGM $(32,12$ e 7,54), plaquetas $(445,5$ e 166,13), leucócitos totais $(15250$ e 5,61), neutrófilos segmentados $(8723$ e 1,44),

\section{Quadro 1. Dados epidemiológicos dos bovinos diagnosticados com Anemia Hemolítica no LPV/LAPAN da UFMT de} 2008 a 2016

\begin{tabular}{|c|c|c|c|c|c|c|c|c|c|c|c|c|c|}
\hline Surto & Localização & $\begin{array}{l}\text { Rebanho } \\
\text { total }\end{array}$ & $\begin{array}{l}\text { Bovinos } \\
\text { no lote }\end{array}$ & $\begin{array}{l}\text { Bovinos } \\
\text { mortos }\end{array}$ & $\begin{array}{l}\text { Mortalidade } \\
\text { (\%) }\end{array}$ & $\begin{array}{c}\text { № } \\
\text { necropsias }\end{array}$ & $\begin{array}{l}\text { Idade } \\
(\mathrm{M} / \mathrm{A})\end{array}$ & $\begin{array}{l}\text { Sexo } \\
M / F\end{array}$ & Pastagem & $\begin{array}{l}\text { Invasão } \\
\text { plantas } \\
\text { daninhas }\end{array}$ & $\begin{array}{c}\text { Cons. } \\
\text { lavoura/ } \\
\text { pecuária }\end{array}$ & $\begin{array}{l}\text { Manejo } \\
\text { do } \\
\text { piquete } \\
\text { após o } \\
\text { surto }\end{array}$ & $\begin{array}{l}\text { Mês/Ano } \\
\text { primeiro } \\
\text { diagnóstico }\end{array}$ \\
\hline 1 & Juína/MT & 600 & 140 & 12 & 8,57 & 2 & $3 \mathrm{~A}$ & $0 / 2$ & Brachiaria spp. & ++ & Não & Roçagem & Jun/2008 \\
\hline 2 & $\begin{array}{c}\text { Nova } \\
\text { Mamoré/RO }\end{array}$ & 500 & 300 & 25 & 5,00 & 1 & Adulto & $0 / 1$ & Brachiaria spp. & +++ & Não & Queima & Out/2012 \\
\hline 3 & $\begin{array}{l}\text { Porto dos } \\
\text { Gaúchos }\end{array}$ & 1.400 & 700 & 40 & 5,71 & 1 & Adulto & $0 / 1$ & Brachiaria spp. & +++ & Não & Lavoura & Jun/2012 \\
\hline 4 & $\begin{array}{l}\text { Porto dos } \\
\text { Gaúchos/MT }\end{array}$ & 10.000 & 149 & 22 & 14,76 & 4 & $\begin{array}{l}6 \mathrm{M} \mathrm{a} \\
8 \mathrm{~A}\end{array}$ & $0 / 3$ & $\begin{array}{l}\text { Brachiaria hibrida } \\
\text { (Convert }^{\mathrm{TM}} \text { HD } 364 \text { ) }\end{array}$ & ++ & Sim & Nenhum & Out/2013 \\
\hline 5 & $\begin{array}{c}\text { Nova } \\
\text { Ubiratã/MT }\end{array}$ & 10.334 & 450 & 3 & 0,66 & 2 & $5 \mathrm{~A}$ & $0 / 2$ & $\begin{array}{l}\text { Brachiaria } \\
\text { ruziziensis }\end{array}$ & + & Sim & Lavoura & Out/2013 \\
\hline 6 & Matupá/MT & 1.200 & 500 & 250 & 50,00 & 1 & $2 \mathrm{~A}$ & $1 / 0$ & Brachiaria spp. & ++ & Sim & Lavoura & Dez/2013 \\
\hline 7 & $\begin{array}{l}\text { Feliz Natal/ } \\
\quad \text { MT }\end{array}$ & 1.500 & 100 & 4 & 4,00 & 1 & Adulto & $0 / 4$ & Brachiaria spp. & +++ & Não & Roçagem & Fev/2014 \\
\hline 8 & Juína/MT & 5.000 & 100 & 50 & 50,00 & 1 & Adulto & $0 / 4$ & Brachiaria spp. & ++ & Não & Lavoura & Mar/2014 \\
\hline 9 & $\begin{array}{c}\text { Terra Nova } \\
\text { do Norte/ } \\
\text { MT }\end{array}$ & 3.700 & 90 & 23 & 25,55 & 2 & Adulto & $0 / 2$ & $\begin{array}{c}\text { Brachiaria } \\
\text { brizanta cv.piatã }\end{array}$ & +++ & Sim & Roçagem & Abr/2016 \\
\hline
\end{tabular}

+ Leve, ++ moderada, +++ intensa; $M / F=$ macho/fêmea, $M / A=$ meses/anos, Cons. = consórcio, Fev = fevereiro, Mar = março, Abr = abril, Jun = junho, Out = outubro, Dez = dezembro. 
neutrófilos bastonetes (174,75 e 234), linfócitos ( 4607 e 2847), eosinófilos (247,75 e 260,05), monócitos (158,12 e 116,42), basófilos ( 0 e 0). O VCM (Volume Corpuscular Médio) apresentou valores acima da normalidade em 3 análises e valores dentro da normalidade em 5 e o CHGM (Concentração de Hemoglobina Globular Média) apresentou valores acima da normalidade em 4 amostras observadas e valores normais nas outras 4 amostras, caracterizando na maioria dos casos anemia normocítica normocrômica. As plaquetas apresentaram valores dentro da normalidade em 7 resultados, observando o aumento destas em somente uma amostra. Os Bovinos 6, $12,13,14,17$ e 18 apresentaram leucocitose com neutrofilia. $\mathrm{Na}$ análise estatística dos valores de enzimas hepáticas e renais dos bovinos avaliados dos Surtos 4 e 9 os valores da média e desvio padrão foram os descritos respectivamente: GGT (220,33 e 161,07), CK (1818,75 e 1086,92), ALT (143 e 39), FA $(270,5$ e 227,26$)$, Albumina $(1,9$ e 0,36$)$, Bilirrubina Total $(6,07$ e 0,60$)$, Uréia $(77,66$ e 26,11$)$, Creatinina $(2,18$ e 0,92$)$, LDH (599 e 281,07). Na análise de enzimas hepáticas, observou-se que Gama glutamiltransferase (GGT), Creatinofosfoquinase (CK), Alanina aminotransferase (ALT) e Fosfatase Alcalina (FA), como também a Bilirrubina total apresentaram valores amuito acima da normalidade. Albumina e Desidrogenase láctica (LDH) apresentaram valores abaixo da normalidade. Com relação aos valores de Uréiae Creatinina houve divergências, notando-se aumento em determinados casos e diminuição em outros. Na pesquisa por hematozoários como Babesiaspp. e Anaplasma spp. e de Trypanossoma sp realizados em 14 bovinos dos 9 surtos o resultado foi negativo. Na urinálise dos bovinos dos Surtos 4, 7 e 9 a coloração da urina apresentou-se mais escurecida em todas as amostras avaliadas, com aspecto predominantemente turvo. $0 \mathrm{pH}$ ácido foi notado somente em uma das amostras de urina avaliadas. Na pesquisa semi-quantitativa a presença de proteínas e sangue na urina foi encontrada em quantidades significativas nas amostras analisadas. Na sedimentoscopia microscópica quantitativa a quantidade de eritrócitos apresentou valores acima da normalidade. Nas técnicas de PCR realizadas para detecção de Leptospira spp. emtrês bovinos dos Surtos 3 e 9 o resultado foi negativo. Nas técnicas de PCR realizadas para detecção de Tripanossoma spp., Babesia spp. e Anaplasma spp. em amostras do DNA extraído de órgãos de três bovinos correspondentes ao Surtos 2, 4 e 5 não houve a detecção destes agentes. Dados detalhados a respeito dos resultados de hemograma, urinálise, enzimas hepáticase de técnicas de PCR estão sumarizados no Quadro 2. A técnica qualitativa do Sulfato de Amônio apresentou resultado positivo para a presença de hemoglobina nas quatro amostras de urina do Surto 4 evidenciando hemoglobinúria. Avaliações da urina de dez bovinos dos Surtos 3, 4, 7 e 9, através de fita reagente $\left(\right.$ Hemagen ${ }^{\circledR}$ ) revelaram $\mathrm{pH}$ ácido e presença de glicose e leucócitos em quantidade leve.

\section{Avaliação anatomopatológica}

Quinze bovinos foram submetidos à necropsia com mínimo de um e máximo de quatro animais por surto. No exame macroscópico de cinco dos quinze bovinos notou-se baixo escore corporal. 0 sangue de quatro destes apresentava coloração vermelho amarronzado com perda da viscosidade e baixa coagulação. As mucosas, ocular, oral e genital, apresentavam palidez acentuada (3/15 casos) e por vezes com moderada icterícia (6/15), também observada na pele do úbere (3/15). Havia ainda leve a moderada icterícia do tecido subcutâneo e camada serosa de vísceras abdominais e torácicas $(6 / 15)$. No fígado se observou aumento de volume (4/15), consistência friável e coloração escura (4/15), por vezes amarelada (6/15) e com evidenciação do padrão lobular (5/15). A superfície de corte mostrou-se intensamente amarela com áreas avermelhadas (6/15). A vesícula biliar estava repleta e com moderado edema de parede $(8 / 15)$. Os rins apresentavam aumento de volume $(3 / 15)$ e coloração marrom escura a enegrecida (9/15) (Fig.1C), apresentando ainda tumefação moderada (4/15), por vezes com áreas de depressão da superfície capsular (2/15). A bexiga continha urina de cor castanho escuro (12/15)(Fig.1D), e o baço estava aumentado até duas vezes o seu tamanho (4/15).

Histologicamente, as lesões no fígado eram caracterizadas por necrose hepatocelular paracentral (13/15 casos), e ocasionalmente centrolobular (9/15)(Fig.1E). Circundando as áreas de necrose haviam hepatócitos tumefeitos e vacuolizados (8/15), além de infiltrado linfoplasmocitário discreto e multifocal (2/15). Pericolangite linfoplasmocitária leve e multifocal $(7 / 15)$ foi observada associada à discreta quantidade de macrófagos espumosos (4/15). Colestase canalicular moderada e multifocal foi observada em 4 casos. Nos rins as lesões foram de nefrose hemoglobinúrica caracterizada por degeneração $(7 / 15)$ e necrose moderada de túbulos uriníferos $(11 / 15)$ com células tubulares com o núcleo picnótico, citoplasma tumefeito e vacuolizado (6/15), por vezes eosinofílico e frequentemente contendo gotículas hialinas (4/15). Notou-se ainda o, material hialino na luz de túbulos (12/15)(Fig.1F), além de áreas focais de calcificação no interstício (1/15) e infiltrado linfoplasmocitário moderado intersticial (6/15). Por fim, no baço havia grande quantidade de substancia castanho claro, caracterizada por hemossiderina dispersa em grande quantidade pelo parênquima, além de discreta quantidade de macrófagos espumosos (7/15),

Nas técnicas de coloração especial do Ácido Rubeânico e Warthin-Starry em todos os casos testados os resultados foram negativos para marcação por traços de cobre em cortes histológicos de fígado e rim, como também para a presença de espiroquetas de Leptospira spp. em cortes histológicos de rim, respectivamente. Na análise qualitativa por método histoquímico com o Azul da Prússia (Reação de Perls) em fragmentos histológicos de fígado e baço, todos os 15 casos testados apresentaram marcação fortemente positiva para a presença de hemossiderina.

\section{DISCUSSÃO}

0 diagnóstico de anemia hemolítica intravascular nos bovinos dos surtos relatados foi realizado por avaliação clínica e patológica dos animais acometidos e confirmada pelos exames hematológicos. As causas de anemia hemolítica em bovinos já relatadas no Brasil foram investigadas e descartadas. Desta forma acredita-se que a doença seja causada por uma planta hemolítica ainda não identificada.

Nos surtos acompanhados, aproximadamente 429 bovinos morreram, de um total de aproximadamente 2.529 animais das propriedades acompanhadas. A morbidade e mortalidade variaram consideravelmente, com índices de 0,57 a $67,11 \%$ e 0,26 a $50 \%$, respectivamente. Já a letalidade apresentou variação de 22 a $100 \%$. Consideráveis perdas econômicas são 
Quadro 2. Resultados de hemograma, enzimas hepáticas e urinálise de bovinos diagnosticados com Anemia hemolítica pelo LPV/LAPAN da UFMT de 2008 a 2016

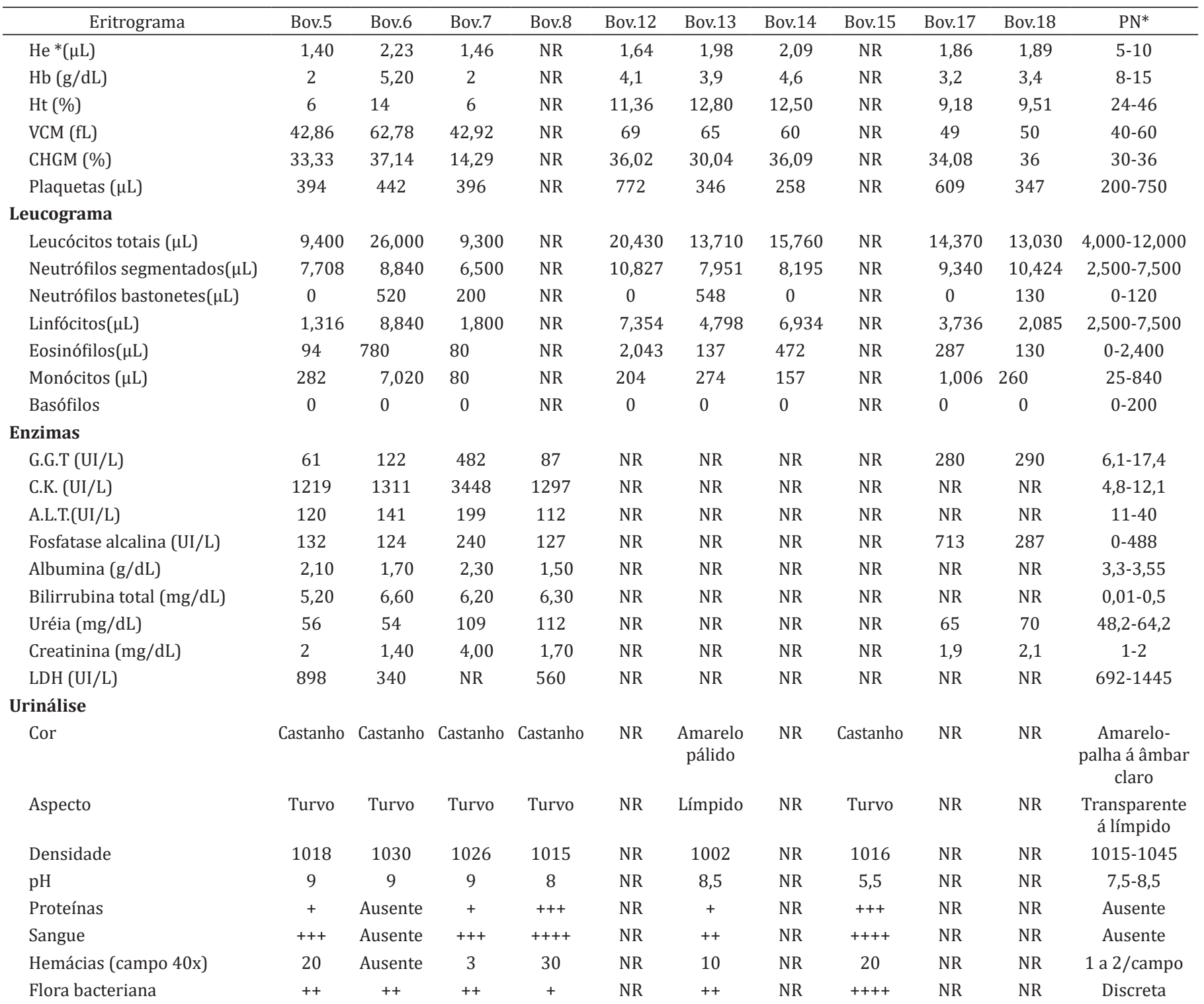

He = hemácias, $\mathrm{Ht}=$ hematócrito, $\mathrm{Hb}=$ hemoglobina, $\mathrm{VCM}=$ volume corpuscular médio, $\mathrm{CHGM}=$ concentração de hemoglobina globular média Bov. 5 = bovino 5, Bov.6 = bovino, Bov.7 = bovino 7, Bov.4 = bovino 4, Bov.8 = bovino 8, Bov.12 = bovino 12, Bov.13 = bovino 13 , Bov.14 = bovino 14 , Bov.15 = bovino 15, Bov.17 = bovino 17, Bov.18 = bovino 18; + traços, ++ leve, +++ moderado, ++++ intenso; *valores de referência; $\mathrm{N}=$ não realizado, IFD = Imunofluorescência direta (imprint rim), hemog = positivo hemoglobina, PN* = padrão de normalidade segundo Weiss \& Wardrop 2011, Lopes et al (2007).

observadas nesses casos, não somente atribuídas às mortes destes bovinos, mas também aos gastos com contratação de médicos veterinários e compra de medicamentos, que na maioria das vezes não são utilizados em função da rápida progressão da doença.

Quanto aos animais afetados, não foi observado predileção por idade ou sexo, contudo, a maior parte dos bovinos afetados foram fêmeas adultas, isso devido ao fato das propriedades acometidas possuírem sistema de cria e recria. Adicionalmente, as nove propriedades mantinham sistema de criação extensiva de bovinos da raça nelore. Em todos os piquetes onde ocorreu a doença, as pastagens eram recém-formadas e compostas por Brachiaria spp. com graus variados de degradação e com leve a intensa invasão por plantas comuns as regiões de Mata Amazônica e transição Cerrado-Amazônia. Esses piquetes frequentemente faziam divisa com áreas mata, ou ainda apresentavam sistema de integração lavoura-pecuária o que favoreceu o contato dos bovinos com plantas tóxicas. Além disso, os casos de anemia hemolítica aconteceram nos meses de outubro a junho, com maior prevalência no mês de outubro, época que corresponde ao início das chuvas nessas regiões e coincide com a brotação de forragens e plantas daninhas. Durante inspeção de pastagens realizadas em visitas às propriedades nenhuma das plantas tóxicas causadoras de 
anemia hemolítica descritas no Brasil foi observada. Dentre elas estão, Allium cepa, que não é cultivada nas regiões onde ocorreram os surtos, Brachiaria radicans, que ocorre somente em áreas alagadas no Pantanal Matogrossensee Ditaxis desertorume Indigofera suffruticosa frequentes na região nordeste do país, e não relatadas nos estados de Mato Grosso e Rondônia. Entretanto, um fato comum a todos os casos era a presença da planta Pleonotoma melioides, conhecido popularmente por "cipó-quatro-quinas. Tal planta, no momento dos surtos estava em fase de brotação e apresentava sinais de consumo pelos bovinos, mesmo em locais onde havia boa disponibilidade de pastagem, demonstrando boa aceitabilidade da planta e talvez maior toxicidade na fase de brotação. Tais indícios levam a crer que esta planta pode estar associada aos casos de intoxicação e estudos adicionais serão realizados na tentativa de reprodução experimental da doença através da administração da planta. Outro fato comum nos surtos é que eles ocorreram em poucos piquetes, sendo que em seis casos, ocorreram somente em um piquete na propriedade. Além disso, os sinais clínicos iniciavam-se poucos dias após a troca de pasto ou introdução de novos bovinos nas áreas. Tal fato pode estar relacionado ao primeiro contato dos animais com a planta, ou com período de estresse e fome vivido por esses animais em momento anterior. Tal característica é vista em algumas intoxicações, como no caso de Brachiaria radicans (Gava et al. 2010).

Após as primeiras mortes, em todos os casos os bovinos foram trocados de pasto. Com essa movimentação, houve a precipitação de algumas mortes e os animais com quadro clinico mais grave morreram por um período de até 15 dias. Entretanto, os demais animais se recuperaram em poucos dias. Essa recuperação após remoção dos animais da área afetada ou mesmo com a continuidade da ingestão da planta é frequentemente relatada em casos de intoxicação por plantas hemolíticas, como Ditaxis desertorum, Indigofera suffruticosa e Brachiaria radicans (Tokarnia et al. 1997, Barbosa Neto et al. 2001, Gava et al. 2010, Figueiredo et al. 2012) e talvez se deva a modificações da flora ruminal que se adapta para alterar a estrutura química do princípio ativo, ainda não conhecido nessas plantas. Tal recuperação corre também em bovinos intoxicados por plantas do gênero Brassica, que contém S-metilcisteína sulfóxido (SMCO), metabólito que no rúmen por ação de bactérias, sofre metabolização em dimetildissulfito, que causa hemólise (Cheeke 1998). A recuperação da anemia em casos de intoxicação por Brassica ocorre, provavelmente, devido a uma adaptação parcial dos microorganismos do rumem produzindo menos dimetildissulfito.

Em cinco propriedades, novos animais foram introduzidos nos piquetes onde ocorreram os surtos, em um período de até 4 meses. Essa introdução foi realizada após manejo de roçagem em três casos, após queima da pastagem em ume sem nenhum manejo em outro caso. Manifestação clínica da doença não foi observada em todos os casos. Acredita-se que a roçagem e a queima das pastagens tenham diminuído a infestação da planta tóxica nas áreas, e ainda, que quando esses animais foram introduzidos nos piquetes, o período mais tóxico da planta tenha passado não havendo manifestação clínica da doença mesmo naquele local em que nenhum manejo foi realizado. Nas propriedades, que não foram substituídas por lavoura e ainda mantinham bovinos nas áreas acometidas, não foi relatadarecorrência da doença, com exceção de uma única propriedade em que houve relatos de casos semelhantes, porém esses casos não foram acompanhados. É possível que a ocorrência de surtos seja limitada a variações pluviométricas, com maior desenvolvimento da planta ou mesmo maior toxidez da mesma em consequência de maior quantidade de chuvas naquelas áreas em períodos específicos. Nesse período nove surtos foram acompanhados, entretanto há relatos de casos semelhantes em várias regiões do Estado de Mato grosso. Acredita-se que muitos outros casos ocorram, porém com a recuperação dos animais após um período, as equipes de diagnóstico não são solicitadas e os casos não são contabilizados.

Quanto as avaliações hematológicas dos casos estudados, observou-se que quadro de anemia normocítica normocrômica na maioria dos casos (Weiss \& Wardrop 2011), o que é compatível com quadros de anemia hemolítica. Os achados de leucocitose por neutrofilia por vezes com desvio para esquerda regenerativo nos Bovinos 6,12,13, 14, 17 e 18 dos Surtos 4, 7 e 9 respectivamente, trata-se de um quadro de leucocitose fisiológica que ocorre frequentemente em bovinos por liberação de glicocorticoides em momentos de estresse durante manejo, transporte (Jain 1993, Buckham-Sporer et al. 2008), como também em processos febris (Ciarlini 2005). Tanto o estresse como quadros febris foram observados nos bovinos deste estudo, em diversas situações como durante o manejo da troca de pasto, manejo de transporte entre fazendas e durante a contenção para a coleta de amostras de sangue. $\mathrm{Na}$ análise de enzimas hepáticas, observou-se que Gama glutamiltransferase (GGT), Creatinofosfoquinase (CK), Alanina aminotransferase (ALT) e Fosfatase Alcalina (FA), como também a Bilirrubina total apresentaram valores muito acima da normalidade. Essas enzimas são de grande uso na rotina clínica, em particular GGT na avaliação de colestase, CK na avaliação de danos hepáticos e Bilirrubina total usada na avaliação de danos hepáticos e com maior elevação em crises hemolíticas (Kaneko 2014).

Resultados negativos na técnica de PCR e na coloração especial para detecção de espiroquetas no rim permitiram descartar a infecção por Leptospira spp. Além disso, os históricos dos casos não informaram alterações reprodutivas frequentes nessa doença (Oliveira et al. 2003, Sandow \& Ramírez 2005). Quanto à hematozoários, a infecção por Babesia spp. e Anaplasma marginale foi excluida, pois, além dos casos analisados não apresentarem lesões patológicas compatíveis com essas infecções (Smith 2006), a pesquisa destes hemocitozoários por esfregaços de sangue apresentou resultados negativos nas amostras analisadas. Adicionalmente o exame de PCR de órgãos de animais acometidos foi negativo à presença destes agentes. Tripanossomíase foi testada e descartada pelos testes de microhematócrito e técnicas de PCR. Nos casos estudados não foram observadas alterações no leucograma compatíveis com tal infecção e ainda não foram observados sinais neurológicos, lesões em meninges (Batista et al. 2008, 2011) ou desordens reprodutivas (Silva et al. 2004, 2013, Cadioli et al. 2012) frequentemente relatadas nessa enfermidade. A suspeita de Hemoglobinúria bacilar foi descartada pela ausência de lesões características dessa doença no fígado (Schild et al. 2008), além da ausência de fascíola ou outros parasitas no órgão (Cullen \& Stalker 2016). Hematúria enzoótica não foi cogitada devido à ausência de alterações vesicais de origem neoplásica (Riet-Correa et al. 2001, 
Gabriel et al. 2009, Galvão et al. 2012, Furlan et al. 2014) e baixa porcentagem ou ausência de infestação das pastagens por Pteridium arachnoideum e P. caudatum nas propriedades onde os surtos ocorreram (Furlan et al. 2014). A intoxicação por cobre foi descartada através da coloração do Ácido Rubeânico que não evidenciou o mineral em tecidos dos animais acometidos.

As manifestações clínicas e patológicas da doença aqui estudada são bastante semelhantes às relatadas nas intoxicações pelas plantas tóxicas hemolíticas descritas no Brasil, e são caracterizadas por quadro de anemia hemolítica aguda, com palidez ou icterícia de mucosas, urina de coloração vermelho escura, assim como fígado e rins que também apresentam colocação vermelho escuro, que correspondem à hemoglobinúria, à necrose de hepatócitos das regiões centrolobular e paracentral e nefrose hemoglobinúrica com proteinúria, respectivamente (Tokarnia et al. 1997, Borelli et al. 2009, Gava et al. 2010, Salvador et al. 2010, Figueiredo et al. 2012). Tais lesões histopatológicas são compatíveis com as alterações de enzimas hepáticas e renais observadas.

\section{CONCLUSÕES}

A anemia hemolítica diagnosticada em bovinos nos estados de Mato Grosso e Rondônia tem considerável impacto nas localidades onde ocorrem, com índices de morbidade e mortalidade razoáveis e alto índice de letalidade.

Os aspectos clinicopatológicos são semelhantes aos descritos para outras plantas tóxicas relatadas no Brasil, entretanto a ausência dessas plantas nas propriedades onde ocorre a doença sugere se tratar de uma planta hemolítica ainda não identificada.

Um fato comum a todas as propriedades investigadas é a presença da planta Pleonotoma melioides que no momento dos surtos estava em fase de brotação e apresentava sinais de consumo pelos bovinos, mesmo em locais onde havia boa disponibilidade de pastagem, demonstrando boa aceitabilidade da planta pelos animais e talvez maior toxicidade na fase de brotação.

Tais indícios levam a crer que esta planta pode estar associada aos casos de intoxicação e estudos adicionais serão realizados na tentativa de reprodução experimental da doença através da administração da planta.

Agradecimentos.- À Coordenação de Aperfeiçoamento de Pessoal de Nível Superior (CAPES) e ao Conselho Nacional de Desenvolvimento Ciêntífico e tecnológico (CNPq) pelo apoio financeiro.

\section{REFERÊNCIAS}

Almeida A.P., Marcili A., Leite R.C., Nieri-Bastos F.A., Domingues L.N., Martins J.R. \& Labruna M.B. 2012. Coxiella symbiont in the tick Ornithodoros rostratus (Acari: Argasidae). Tick sand tick-borne Dis. 3(4): 203-206.

Alward A., Corriher C.A., Barton M.H., Sellon D.C., Blikslager A.T. \& Jones S.L. 2006. Redmaple (Acer rubrum) leaftoxicosis in horses: a retrospectivestudyof 32 cases. J. Vet. Intern. Med. 20(5):1197-1201.<http:// dx.doi.org/10.1111/j.1939-1676.2006.tb00722.x><PMid:17063716>

Aquino Neto H.M., Freitas M.D. \& Sanches I.X.B. 2014. Considerações sobre intoxicação crônica por cobre em ovinos. Revta Col. Ciênc. Anim. 7(1):98-107.

Barbosa Neto J.D., Oliveira C.M.C., Peixoto P.V., Barbosa I.B.P., Ávila S.C. \& Tokarnia C.H. 2001. Anemia hemolítica causada por Indigofera suffruticosa (Leg. Papilionoideae) em bovinos. Pesq. Vet. Bras. 21(1):18-22. <http:// dx.doi.org/10.1590/S0100-736X2001000100005>
Batista J.S., Bezerra F.S.B., Lira R.A., Carvalho J.R.G., Rosado Neto A.M., Petri A.A. \& Teixeira M.M.G. 2008. Aspectos clínicos, epidemiológicos e patológicos da infecção natural em bovines por Trypanosoma vivax na Paraíba. Pesq. Vet. Bras. 28(1):63-69. <http://dx.doi.org/10.1590/S0100736X2008000100010>

Batista J.S., Rodrigues C.M.F., García H.A., Bezerra F.S.B., Olinda R.G., Teixeira M.M.G. \& Soto-Blanco B. 2011. Association of Trypanosoma vivax in extracellular sites with central nervous system lesions and changes in cerebrospinal fluid in experimentally infected goats. Vet. Res. 42(1):63. <http://dx.doi.org/10.1186/1297-9716-42-63><PMid:21569364>

Berenguer Piqueras M., Cabañas Perianes V., Moya Arnao M. \& Salido Fiérrez E. 2016. Actualización en anemias hemolíticas. Medicine. Programa de Formación Médica Continuada Acreditado 12(20):1148-1158. <http:// dx.doi.org/10.1016/j.med.2016.10.003>

Borelli V., Lucioli J., Fernando H.F., Patrícia G.H., Juliano F.R., Sandra D.T. \& Gava A. 2009. Fatal onion (Allium cepa) toxicosis in water buffalo (Bubalus bubalis). J. Vet. Diagn. Invest. 21(3):402405. <http://dx.doi. org/10.1177/104063870902100321><PMid:19407101>

Buckham-Sporer K.R., Weber P.S.D., Burton J.L., Early B. \& Crowe M.A.2008. Transportation of young beef bulls alters circulating physiological parameters that may be effective biomarkers of stress. J. Anim. Sci. 86(6):1325-1334. <http://dx.doi.org/10.2527/jas.2007-0762> <PMID: 18344301>

Burrows G.E. \& Tyrl R.J. 2013. Toxic Plants of North America. 2nd ed. John Wiley and Sons, New Jersey, p.290, p.754-755.

Cadioli F.A., Barnabé P.A., Machado R.Z., Teixeira M.C.A., André M.R., Sampaio P.H., Fidélis Junior O.L., Teixeira M.M.G. \& Marques L.C. 2012. First report of Trypanosoma vivax outbreak in dairy cattle in São Paulo state, Brazil. Revta Bras. Parasitol. Vet. 21(2):118-124. <http://dx.doi.org/10.1590/ S1984-29612012000200009><PMid:22832751>

Cheeke P.R. 1998. Natural Toxicants in Feeds, Forages, and Poisonous Plants. 2nd ed. Danville, Illinois, p.302-306.

Ciarlini P.C., Antonio D.B.A., Barbiere F., Bonello F.L. \& Feitosa F.L.F. 2005. Efeito da vacina contra brucelose bovina sobre a capacidade neutrofílica de redução do NBT. Ars Vet. 21(2):251-256.

Cortez A.P., Rodrigues A.C., Garcia H.A., Neves L., Batista J.S., Bengaly Z., Paiva F. \& Teixeira M.M. 2009. Cathepsin L-like genes of Trypanosoma vivax from Africa and South America: characterization, relationships and diagnostic implications. Molec. Cel. Probes 23(1):44-51. <http://dx.doi. org/10.1016/j.mcp.2008.11.003><PMid:19063960>

Cullen J.M. \& Stalker M.J. 2016. Hemapoetic system, p.258. In: Maxie M.G. (Ed.), Jubb, Kennedy and Palmer's Pathology of Domestic Animals. Vol.3. 6th ed. St Louis, Missouri.

DeWitt S.F., Bedenice D. \& Mazan M.R. 2004. Hemolysisand Heinz body formation associated with ingestion of red maple leaves in two alpacas. J. Am. Vet. Med. Assoc. 225(4):578-583. <http://dx.doi.org/10.2460/ javma.2004.225.578><PMid:15344367>

Figueiredo A.P., Medeiros R.M., Dantas F.P., Leite A.L., Fighera R.A. \& Riet-Correa F. 2012. Intoxicação experimental por Indigofera suffruticosa em caprinos e ovinos. Pesq. Vet. Bras. 32(2):126-130. <http://dx.doi.org/10.1590/ S0100-736X2012000200006>

Fry M.M. \& McGavin M.D. 2013. Bone marrow, blood cells, and lyphatic system, p.716-732. In: Zachary J.F. \& McGavin M.D. (Eds), Pathologic Basis of Veterinary Disease. 6th ed. Elsevier.

Furlan F.H., Costa F.L., Torres Junior S.C.S., Kerber F.L., Damasceno E.S., Salino A. \& Riet-Correa F. 2014. Perfil de propriedades rurais com pastos invadidos por Pteridium arachnoideum na região norte de Mato Grosso e prevalência de hematuria enzoótica bovina. Pesq. Vet. Bras. 34(8):753-759. <http:// dx.doi.org/10.1590/S0100-736X2014000800008>

Gabriel A.L., Kommers G.D., Masuda E.K., Fighera R.A., Piazer J.V.M., Barros C.S.L., Martins T.B. \& Rosa F.B. 2009. Aspectos clínico-hematológicos e lesões vesicais na intoxicação crônica espontânea por Pteridium aquilinum 
em bovinos. Pesq. Vet. Bras. 29(7):515-525. <http://dx.doi.org/10.1590/ S0100-736X2009000700005>

Galvão A., Brito M.D.F., Aragão A.P., Yamasaki E.M., Peixoto P.V. \& Tokarnia C.H. 2012. Sobrevivência/viabilidade de bovinos com hematúria enzoótica após transferência para região livre de Pteridium arachnoideum. Pesq. Vet. Bras. 32(9):887-902. <http://dx.doi.org/10.1590/S0100-736X2012000900013>

Gava A., Deus M.R.S., Branco J.V., Mondadori A.J. \& Barth A. 2010. Intoxicação espontânea e experimental de Brachiaria radicans ("Taner grass") em bovinos. Pesq. Vet. Bras. 30(3):255-259. <http://dx.doi.org/10.1590/ S0100-736X2010000300012>

Jain N.C. 1993. Essentials of Veterinary Hematology. 5th ed. Lea and Febiger, Philadelphia. 417p.

Kaneko J.J. 2014. Clinical Biochemistry of Domestic Animals, 3rd ed. Elsevier Academic Press, p.351-378.

Lopes S.T., Biondo A.W. \& Santos A.P. 2007. Manual de Patologia Clínica Veterinária. 3a ed. UFSM, Santa Maria, RS, p.69.

Melo A.L.T., Witter R., Martins T.F., Pacheco T.A., Alves A.S., Chitarra C.S., Dutra V., Nakazato L., Pacheco R.C., Labruna M.B. \& Aguiar D.M. 2016. A surveyoftick-borne pathogens in dogs and theirticks in the Pantanal biome, Brazil. Med. Vet. Entomol. 30(1):112-116. <http://dx.doi.org/10.1111/ mve.12139><PMid:26467462>

Oliveira M.A.A., Caballero O.L., Vago A.R., Harskeerl R.A., Romanha A.J., Pena S.D.J., Simpson A.J.G. \& Koury M.C. 2003. Low-stringency single specific primer PCR for identification of Leptospira. J. Med. Microbiol. 52(2):127135. <http://dx.doi.org/10.1099/jmm.0.04923-0> <PMid:12543918>

Prophet E.B., Mills B., Arrington J.B. \& Sobin L.H. 1992. Laboratory methods in Histotechnology. Armed Force Institute of Pathology, Washington, DC. 279p.

Riet-Correa F., Schild A.L., Méndez M.C. \& Lemos R.A. 2001. Doenças de Ruminantes e Equinos. Vol.1 e 2. 2ª ed. Livraria Varela, São Paulo.

Salvador I.S., Medeiros R.M.T., Pessoa C.R.M., Dantas A.F.M., Sucupira Júnior G. \& Riet-Correa F. 2010. Intoxicação por Indigofera suffruticosa (Leg. Papilionoideae) em bovinos. Pesq. Vet. Bras. 30(11):953-957. <http:// dx.doi.org/10.1590/S0100-736X2010001100009>

Sambrook J. \& Russel D.W. 2001. Molecular Cloning: a laboratory manual. Vol.1-3. Cold Spring Harbor Laboratory Press, New York.

Sandow K. \& Ramírez W. 2005. Leptospirosis. RedVet. 6(6):1-6. Disponível em <http:// www.veterinaria.org/revistas/redvet/n060605.html> Acesso em 1 fev. 2016.
Schild A.L., Ruas J.L., Farias N.A., Grecco F.B. \& Soares M.P. 2008. Aspectos epidemiológicos de um surto de babesiose cerebral em bovines em zona livre de carrapato. Ciência Rural 38(9):2646-2649. <http://dx.doi. org/10.1590/S0103-84782008000900041>

Shi Y., Lan F., Matson C., Mulligan P., Whetstine J.R., Cole P.A., Casero R.A. \& Shi Y. 2004. Histone demethylation mediated by the nuclear amine oxidase homolog LSD1. Cell 119(7):941-953. <http://dx.doi.org/10.1016/j. cell.2004.12.012><PMid:15620353>

Silva J.B., Cordeiro M.D., Manier B.S.M.L., Valim J.R.A., Bomjardim H.A., Fonseca A.H. \& Barbosa J.D. 2015. Detecção sorológica de Anaplasma marginale, Babesia bovis e Babesia bigemina em bovinos de corte das regiões Norte e Centro Oeste do Brasil. Semina, Ciênc. Agrárias 36(3):1431-1436.

Silva R.A.M.S., Pellegrin A.O., Ramirez E.S.S.L.L. \& Dávila A.M.R. 2004. Abortos por Trypanosoma vivax no Pantanal Mato-Grossense e Bolívia. Doc.75, Embrapa Pantanal, Corumbá, MS. 30p.

Silva T.M.F., Olinda R.G., Rodrigues C.M.F., Câmara A.C.L., Lopes F.C., Coelho W.A.C., Ribeiro M.F.B., Freitas C.I.A., Teixeira M.M.G. \& Batista J.S. 2013. Pathogenesis of reproductive failure induced by Trypanosoma vivaxin experimentally infected pregnant ewes. Vet. Res. 44(1):1. <http://dx.doi. org/10.1186/1297-9716-44-1><PMid:23289625>

Smith B.P. 2006. Medicina Interna de Grandes Animais. $3^{\text {a }}$ ed. Manole, Barueri, SP. 1784p.

Stoddard R.A., Gee J.E., Wilkins P.P., McCaustland K. \& Hoffmaster A.R. 2009. Detection of pathogenic Leptospira spp. through TaqManpolymerase chain reaction target in the Lip32 gene. Diagn. Microbiol. Infect. Dis. 64(3):247-255.<http://dx.doi.org/10.1016/j.diagmicrobio.2009.03.014> $<$ PMid:19395218>

Tokarnia C.H., Chagas B.R., Chagas A.D. \& Silva H.K. 1997. Anemia hemolítica causada por Ditaxis desertorum (Euphorbiaceae) em bovinos. Pesq. Vet. Bras. 17(3/4):112-116. <http://dx.doi.org/10.1590/S0100-736X1997000300004>

Tokarnia C.H., Brito F.M., Barbosa J.D., Peixoto P.V. \& Döbereiner J. 2012. Plantas Tóxicas do Brasil. $2^{\text {a }}$ ed. Helianthus, Rio de Janeiro. 586p.

Weber M. \& Miller R.E. 1997. Presumptive red maple (Acer rubrum) toxicosis in Grevy's zebra (Equus grevyi). J. Zoo Wildl. Med. 28(1):105108. <PMid:9226625>

Weiss D.J. \& Wardrop K.J. 2011. Schalm's veterinary hematology, chapter 107. Normal Hematology of Cattle. 6th ed. John Wiley and Sons. 1232p. 